\title{
A Review of Contra Instrumentalism: A Translation Polemic
}

\author{
Haihong Yin ${ }^{1}$ \\ ${ }^{1}$ School of Interpreting \& Translation Studies, Guangdong University of Foreign Studies, Guangzhou, \\ Guangdong, China \\ Correspondence: Haihong Yin, School of Interpreting \& Translation Studies, Guangdong University of Foreign \\ Studies, Baiyun Avenue North 2, Baiyun District, Guangzhou, Guangdong, China. E-mail: \\ haihongyin2011@163.com
}

\author{
Received: September 8, $2021 \quad$ Accepted: October 20, $2021 \quad$ Online Published: November 4, 2021 \\ doi:10.5539/ells.v11n4p61 URL: https://doi.org/10.5539/ells.v11n4p61
}

Contra Instrumentalism: A Translation Polemic By Lawrence Venuti, Lincoln, University of Nebraska Press, 2019. 216 PP., \$20.00 (paperback), ISBN: 978-1-49620-513-1, \$20.00 (eBook), ISBN: 978-1-49621-594-9.

\begin{abstract}
Contra Instrumentalism: A Translation Polemic is the latest monograph of Venuti. It firstly examines the "untranslatability" and "loyalty" widely existing in translation theories, translation proverbs, and subtitle translation. Then the work criticizes the instrumentalism behind them, and proposes to think translation in a hermeneutic way. This review mainly introduces the general idea of each part, the structure and methodology of this book, and gives a brief comment on its value, shortcomings, enlightenment as well.
\end{abstract}

Keywords: Venuti; Untranslatability; instrumentalism; hermeneutic model

Venuti's new book Contra Instrumentalism: A Translation Polemic (2019) is one of the "Provocations" series published by Nebraska Press. With incisive criticism and strong arguments, the book intends to challenge the predominant instrumentalism in translation. At the same time, it advocates the hermeneutic model by evoking a fundamental change in the way people think of translation.

Apart from the "Acknowledgements" and "Provocations" sections, this book is constituted of the "START/STOP" part in front, "STOP/START" part in the end, and three major chapters in the middle. In "Provocations", Venuti reveals the misunderstanding, stigmatization, and prejudice that translation has suffered for millennia. The "START/STOP" chapter provides a general introduction to the book as a whole. Beginning with a brief explanation of the difference between the instrumental model and the hermeneutic model, Venuti makes it clear that the aim of his book is to "put an end to the dominant instrumentalist thinking in translation" (p. 5), and in the meanwhile to appeal to people to adopt the hermeneutic model of translation. Then, he explains that the key concepts of the hermeneutic model are mainly based on semiotics and post-structuralism, and the methodology is built on Foucauldian archaeology. The materials in his argument touch on the languages and cultures of Arabic, Danish, French, Italian, German, Greek, Korean, Latin, and Spanish. He believes his model could be applied globally, though his focus and discussion mainly concern the current situation in the US.

In the first chapter, entitled "Hijacking Translation", Venuti begins with a brief review of the relationship between translation and comparative literature in the US. He points out that the marginalized position of translation in the fields of comparative literature and world literature persisted in US until the past decade. Centering on a translation of Barbara Cassin's Dictionary of Untranslatables (2014), Venuti then explains why and how translation is "hijacked" in the US. By demonstrating various situations of untranslatability and mistranslation that American scholars like Emily Apter, Michael Wood, and Samuel Weber described, he argues that any "translation analysis raises more questions than it answers" (p. 56), only because all analyses, comments, and criticism about translation are unconsciously manipulated by the instrumental model. In this way, translation studies never give up the utopian aspiration and instrumentalist assumption of reproducing the "invariant" (something can be transferred directly and completely through translation). The instrumental model therefore leads to translation criticism that is full of contradictions and confusion by stressing untranslatability, invariance, and equivalence, or by pointing out errors under different translation unit. 
Venuti chooses to argue with some American instrumentalists by analyzing their remarks, comments, or essays, since the real "hijacking" always happens in translation practices and studies. He accuses Apter as well as Wood of equating "untranslatability to repeated, relentless translation" (p. 65). By constantly emphasizing untranslatability and mistranslation, Venuti thinks the significant role of translation has been neglected in many fields for years. He argues that only when people realize "a text can support many different interpretations" (p. 75) and "translation changes both the form and meaning", can the marginalized and neglected situation that translation has been facing be changed to any degree.

The second chapter, "Proverbs of Untranslatability", discusses the untranslatability of proverbs by analyzing their features as a genre. It focuses on the relations between the "clichéd thinking behind proverbs and the instrumental model of translation" (p. 85). By tracing the genealogy of three particularly influential proverbs, the author tries to illuminate how translation has been dominated by the rote thinking behind these popular proverbs.

The well-known Italian proverb "traduttore, traditore", usually translated as "translators, traitors", is cited frequently by translators, theorists, and poets. This proverb contributes greatly to the instrumentalist assumption of formal and semantic invariance, which inhibits people from regarding translation as an interpretive act. By tracing the genealogy of "traduttore, traditore" and analyzing it from the basis of metaphysics, Venuti shows how this proverb gradually became a symbol of instrumentalism to limit the way people think of translation. Another widely used proverb, "poetry is what is lost in translation"-usually attributed to Robert Frost-conceals the function of translation with a metaphor of loss. "Most citations assume that the proverb is self-explanatory" (p. 110), but Venuti chooses to explore its implications through lectures, interviews, letters, and comments from Frost himself as well as his friends. He concludes that Frost's famous proverb is built on the assumptions of an instrumental model as "his instrumentalism prevented him from perceiving aspects of his vernacular poetics that would have challenged his understanding of translation" (p. 115). The third proverb is Jacques Derrida's sophisticated statement: "in a sense, nothing is untranslatable; but in another sense, everything is untranslatable". Venuti maintains that this theoretical statement from Derrida may "rest on two models simultaneously", which causes "contradiction and logical discontinuity at the epistemic level" (p. 120) and divulges a paradox between Derrida's theoretical concepts and practices.

With case studies of the three popular proverbs, Venuti clarifies that an assertion of a source text being untranslatable often presupposes an instrumental model that enables translation to be treated as always unsuccessful. Meanwhile, the underlying instrumental model in these proverbs provokes suspicion about the linguistic competence of translators and gives rise to notions of untranslatability (p. 119).

The third chapter, "The Trouble with Subtitles", draws attention to the problems of research and training in the field of subtitle translation. Subtitle translation requires transformation not only "from one language to another", but also "from the spoken mode to the written mode" (p. 127), which usually involves a quantitative dialogue reduction or condensation. In fact, interpretative action is quite common in the practice of subtitle translation, whereas the old subtitling conventions are still supported by "film distribution companies, translator training programs, and validated by film critics, translation instructors and subtitlers themselves" (p. 162). Taking experienced subtitler Henrik Gottlieb as a case study, Venuti insists that the ubiquitous instrumental model in subtitle translation "must be abandoned if the study, teaching and practicing of subtitling are to advance" (p. 130). Furthermore, he uses six films as examples, including popular ones like Psycho, Annie Hall, and Rififi to discuss the problems and challenges subtitling is facing.

As a distinct genre, subtitle translation "entails shifting between source and receiving text" (p. 135), which requires interpretation. Subtitlers like Henri Béhar, Lenny Borger, Esther Kwon and Wonjo Jeong have contributed to interpretative subtitling with their own understanding and style, but their efforts are neither appreciated by viewers nor admitted by film critics, audiovisual translators, trainers, or scholars. After Analyzing some interviews and commentary, Venuti points out that subtitlers are unwilling to question subtitling conventions, even though they perform their work in an interpretive way, which shows the evident contradiction between notion and practice. On the one hand, under the instrumental model, current subtitling research, teaching, and practice fail to take complicated factors of both source and receiving cultures into consideration. On the other hand, subtitling provides a wide range of "interpretive possibilities to subtitlers". The hermeneutic model can therefore help to explore those possibilities and expose the manifold conditions, since a hermeneutic model automatically presumes that "translation is transformation" (p. 136).

In addition, Venuti in this chapter touches on issues like the negative effects of fansubbing (subtitling by fans) and multimodal transcription in subtitling. At the same time, his discussion raises the following questions to readers: Do we have to seek a correspondence between subtitles and speech in a film soundtrack? Could we 
require viewers to change their preconceptions about subtitles? His exploration undoubtedly provides a new angle to think about audiovisual translation, which is significant to the practice's further development.

In the very last part of the book, "STOP/START", Venuti stresses that the purpose of his argument and critique is to trigger a departure from instrumentalism in translation theory and "pursue new ways of thinking about translation based on the hermeneutic model" (p. 173). Just as Dudley Andrew remarks in the front-page foreword that "the truth is that there is no truth, only interpretation", Venuti points out that there is no invariant in a source text, no text should be conceived as something untranslatable, and no translation could be equivalent or identical to a source text. He then proposes to change the intellectual habits and commonsensical view of translation dominated by instrumentalism, and to view translations as independent texts or multiple interpretations. Translation should be evaluated or commented not only from the perspective of source text but also from readers, institutions, receiving cultures, values and beliefs.

Tangling with translators, scholars, and some high-wire philosophers of language about their seemingly indisputable assumptions of what a translation is and does, this polemic seeks to develop a hermeneutic model of translation, which presupposes translation as indirect, mediated, and variant interpretation. In this book, Venuti demonstrates that the fundamental reason behind long-term arguments about translation is the instrumental assumption of an invariant, which is not actually contained in the source text. This could be considered as one of the most prominent contributions to the book. Meanwhile, based on the methodology of Foucauldian archaeology and supported by sufficient first-hand materials and examples, this book almost covers all of the core issues in translation history. Furthermore, the book is organized with a distinct structure. The part of START/STOP in the beginning and STOP/START part in the end allow the author to have direct dialogue with readers, which makes his illustrations clear and persuasive.

However, instead of offering a reliable definition of interpretation or making specific distinctions between translation and interpretation, the book seemingly expends too much effort to explain what instrumentalism is, which inevitably involves repetitive descriptions and statements along with abundant case studies. Although some subjective comments, unpersuasive examples, and incomplete deductions can be found in the book, as is typical for a polemic, it will not only make readers reconsider what translation is and does, but also arouse people's desire to change the way they view translation. Therefore, Venuti's new book is definitely worthy of attention, and its significance to translation studies should not be neglected.

\section{Reference}

Cassin, B. (Ed.). (2014). Dictionary of Untranslatables: A Philosophical Lexicon (trans. Steven Rendall et al.). Princeton NJ: Princeton University Press.

\section{Copyrights}

Copyright for this article is retained by the author, with first publication rights granted to the journal.

This is an open-access article distributed under the terms and conditions of the Creative Commons Attribution license (http://creativecommons.org/licenses/by/4.0/). 